\title{
Influences of wind speed and direction on atmospheric particle concentrations and industrially induced noise
}

\author{
Ayansina Ayanlade ${ }^{*}$ and Ebunoluwa Folasade Oyegbade
}

\author{
*Correspondence: \\ aayanlade@oauife.edu.ng; \\ sinaayanlade@yahoo.co.uk \\ Department of Geography, \\ Obafemi Awolowo University, \\ Ile-Ife, Nigeria
}

\begin{abstract}
Purpose: In this study, the spatial and temporal relationship of wind speed, atmospheric particles concentration, and the industrial-induced noise levels during different times of the day were examined, using sawmill industrial location around lle-lfe in Osun of Nigeria as a case study.

Methods: Mobile devices were used to measure noise level and basic meteorological parameters were examined and their influences on the noise levels distribution were assessed. The maximum and minimum sound levels; $L_{\max }$ and $L_{\text {min, }}$ the $P M_{10}$ and $\mathrm{PM}_{1}$ particle concentrations, wind speeds and directions were measured in the morning (7-9 a.m.), afternoon (12-2) and evening (4-6 p.m.) over 14 consecutive days.
\end{abstract}

Results: The results revealed that the noise level varies spatiotemporally, much more consistent spatial distribution along the vicinity of sawmill industries. A higher level of noise occurred during the weekday (WD), $\mathrm{L}_{e q}>70 \mathrm{~dB}(\mathrm{~A})$, compared to weekends (WE). Extreme average noise levels are associated with the immediate neighbourhood of sawmill industrial areas during WD compared to streets and road annexes of the study area. The results also show a very weak relationship between noise and $\mathrm{PM}_{10}$ and $\mathrm{PM}_{\text {coarse }}$ for both WD and WE with $r<0.35$ for $\mathrm{PM}_{1}$ and $r<0.20$ for $\mathrm{PM}_{\text {coarse. }}$ There appears to be a moderate significant correlation between noise level and $\mathrm{PM}_{1}$ during some meteorological conditions with $r>0.51$.

Conclusion: The slight relationship between noise and $\mathrm{PM}_{1}$ is perhaps a result of wind movement that carries particles from the source region since booth noise and particles mostly originate from the sawmill. The study concludes that wind speeds and directions have a significant influence on both noise level and particle concentration within the study sites.

Keywords: Wind speed/direction, Atmospheric particles, Turbulent, Noise levels

\section{Background}

Noise pollution has been one of the environmental hazards as early as the inception of civilization to the recent era of technology. Noise pollution has been associated with human activities and persistent human interaction with the environment. Over the past decades, noise pollution has received increased attention and studies have reported that noise pollution is one of the environmental hazards affecting human, the effects range from annoyance to difficulty in falling asleep, which latter leads to high blood pressure

(c) The Author(s) 2016. This article is distributed under the terms of the Creative Commons Attribution 4.0 International License (http://creativecommons.org/licenses/by/4.0/), which permits unrestricted use, distribution, and reproduction in any medium, provided you give appropriate credit to the original author(s) and the source, provide a link to the Creative Commons license, and indicate if changes were made. 
(WHO 2005; Ugwuanyi et al. 2005; Den Boer and Schroten 2007; Tetreault et al. 2013). Studies have stated that noise pollution causes hearing impairment, physiological and mental illness, and in many cases prompts behavioural and social effects (Den Boer and Schroten 2007; Pathak et al. 2008; Weber 2009; Ballesteros et al. 2010; WHO 2011, 2013; Lee 2014). A study by De Vos and Van Beek (2011) has revealed that about two billion people in cities around the world are subject to over $55 \mathrm{~dB}(\mathrm{~A})$ noise level. But, a report by the European Environment Agency, EEA (2014) estimated that nearly 115 million people in Europe are exposed to average day/night time noise levels of about $55 \mathrm{~dB}(\mathrm{~A})$. The findings from these studies revealed that noise pollution is severe in urban areas, especially in less developed countries where insufficient control is exercised, mainly if the cities are poorly planned (Pathak et al. 2008; Foraster 2013).

The need to understand environmental noise and its impacts on people in urban areas has driven other researchers in both developed and developing countries. In developed countries, several noise pollution guidelines have been developed. In sub-Saharan Africa, although, where noise legislations exist, they are often poorly enforced and implemented (Sonibare et al. 2004; Chung et al. 2005; Oyedepo and Saadu 2009; Sørensen et al. 2011; Oyedepo 2012). However, interest may be attributed to the current development of guidelines and standards for environmental pollution by the Federal Environmental Protection Agency (FEPA 1991). Unlike cities in developed countries, surprisingly, few studies have been carried out in sub-Saharan Africa which assessed spatial and temporal patterns in noise level and relate this to meteorological parameters. There is a need for examination of atmospheric air pollution and environmental noise, their relationship and how this could affect cities inhabitants. Thus, this study aims at evaluating the spatial and temporal variations in the noise levels during different times of the day and examines influences of the wind on industrial-induced noise pollution in sawmills industrial location around Ile-Ife in Osun of Nigeria. The study focuses on assessing the spatiotemporal relationship between wind speed and direction and noise level and determine the extent noise and particles have a common cause. The basic meteorological parameters were examined and their influences on the distribution of industrial-induced and traffic noise were assessed.

\section{Methods}

The sites are within Ita-Osa and Erefe communities of Ile-Ife in Osun, Nigeria (Fig. 1). Climate regime in this area is tropical humid climate. The mean annual rainfall is bimodal in nature with peaks in July (average of $350 \mathrm{~mm}$ ) and September (average of $200 \mathrm{~mm}$ ). The mean minimum temperature ranges from $20{ }^{\circ} \mathrm{C}$ in January to $23{ }^{\circ} \mathrm{C}$ in February, while the mean maximum for the hottest month is $28.6^{\circ} \mathrm{C}$ (Adejuwon and Jeje 1975; Ojo 1977). One of the major activities within the communities is the enormous sawmills industries, due to the proximate of the area to tropical forest exploitation and lumbering. Samples were chosen from Ita-Osa and Erefe, out of many communities in IELG because the communities are the major location where sawmills industrial activities are been carried out in IELG. Noise level and atmospheric particles concentration were measured simultaneously, using mobile sensors. The measurements were taken along sawmill industrial locations, at some road junctions, and some residential areas for approximately $45 \mathrm{~min}$ at a time. A set of digital mobile noise meters (SET 1350) was 


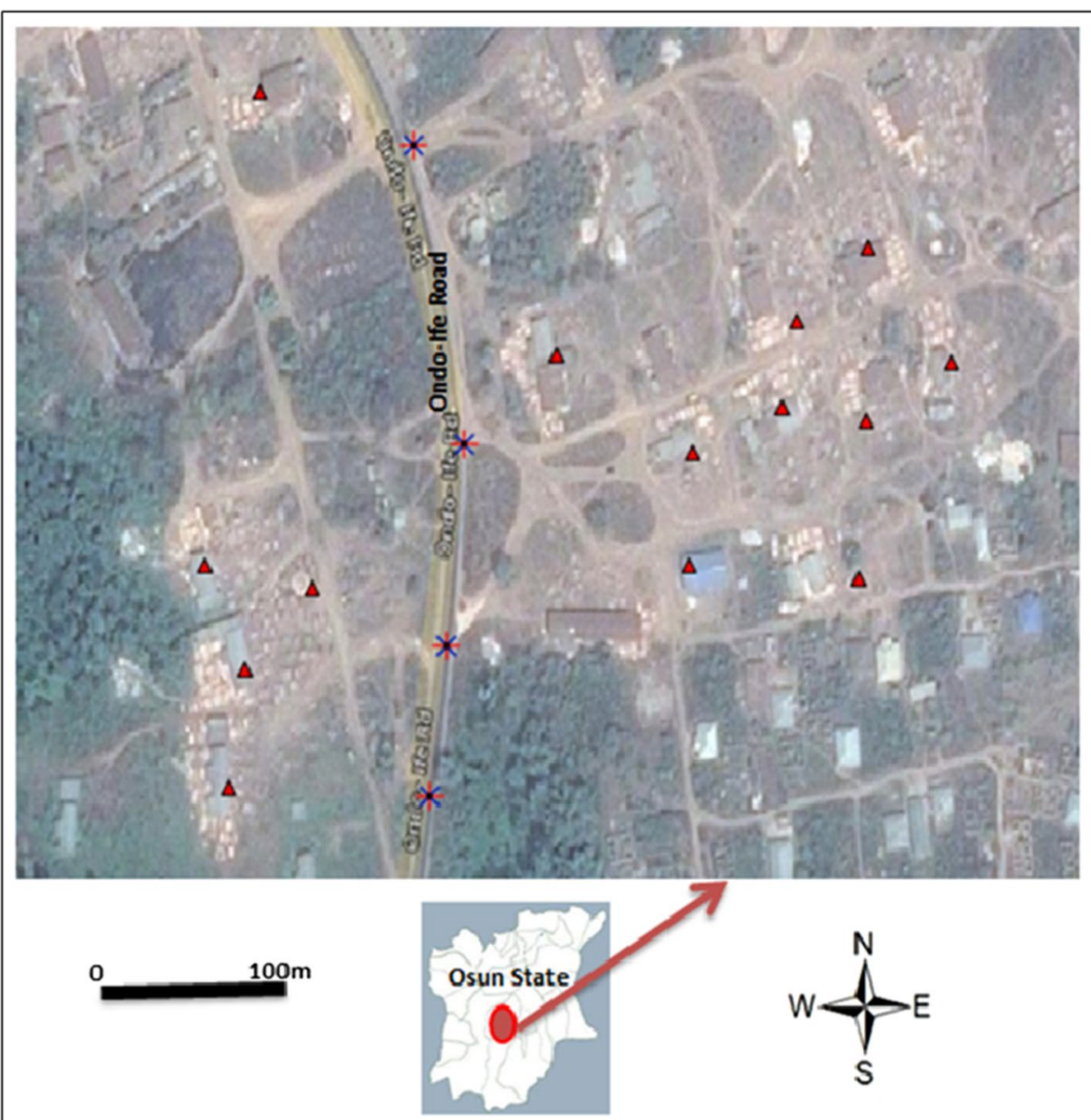

Fig. 1 Maps of the study site. Map of Osun state in green. Triangles represent locations of sawmill industrial engines while star symbols represent locations of measurements along the roadsides. Modified from Google earth

used to measure noise level at ten repeated points (Fig. 2a). The types of sound level meter used are the typical mobile type which consists of a microphone for picking up the sound and convert into an electrical signal. The device is calibrated to read the sound level in $\mathrm{dB}(\mathrm{A})$. The noise meter had a measuring level range of $35-130 \mathrm{~dB}(\mathrm{~A})$ with Accuracy up to $\pm 1.5 \mathrm{~dB}$. In every measuring location, the microphones were pointed in the general direction of the noise source at a distance, not less than $1 \mathrm{~m}$ away from any reflecting objects. At the start of measurement, noise levels were measured first at the position of the machines at sawmill and other measurements were taken at intervals of 30 feet outward from each sawmill, in all directions, in the morning (7-9 a.m.), afternoon (12-2) and evening (4-6 p.m.) during 14 consecutive days (from Monday to Sunday). The maximum and minimum sound levels $\left(\mathrm{L}_{\max }\right.$ and $\left.\mathrm{L}_{\min }\right)$, were measured, the highest and the lowest time-weighted sound levels were also measured in $\mathrm{dB}(\mathrm{A})$ while the equivalent sound pressure level $\mathrm{L}_{\mathrm{eq}}$ were also calculated for different time slices.

Revisiting the sample locations was guided by Global Positioning System (GPS). Sets of Garmin GPSs with $0.2 \%$ resolution accuracy (Fig. 2c) were used in the field to locate 


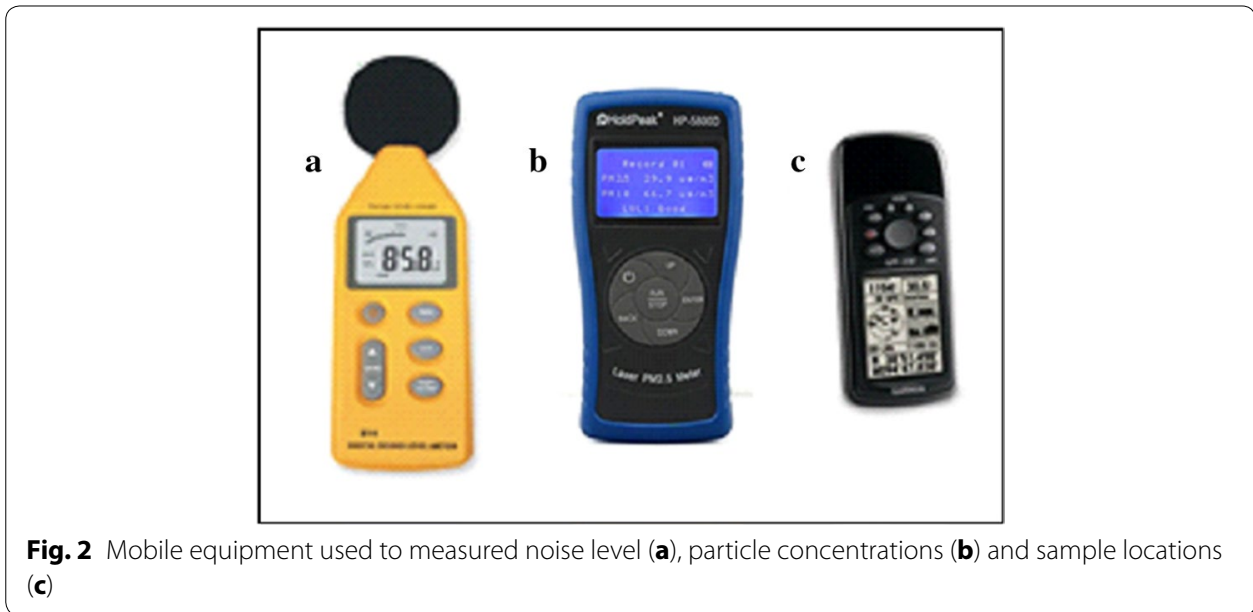

sample points and record the coordinates of all sample points for effective mapping. Noise levels for both weekdays (WD) and weekends (WE) were mapped using inverse distance weighting (IDW) interpolation technique as stated by Burrough and Rachael 1998; Ayanlade 2009; Samanta et al. 2012; Pokhrel et al. 2013. This was performing in Quantum GIS environment. IDW was calculated using weights change which was based on the linear distance of the noise sample points from the unsampled points in inverse proportions. The implication of this on noise measurement is that noise level values closer to the un-sampled locations are more representative of the value to be estimated than values from samples farther away. Thus, IDW was used to interpolate deviations from a long-term mean in noise level data over the study periods.

The measurement of wind speed, direction and turbulence were carried out using set mobile anemometers which were installed on poles at a height of $3.75 \mathrm{~m}$, with a $1 \mathrm{~min}$ resolution. This implies that the wind data were gathered above rooftop height and within the street. The $\mathrm{PM}_{10}$ and $\mathrm{PM}_{1}$ concentrations were measured using mobile optical particle counters. A Set of HP 5800D PM2.5/PM10/Formaldehyde Monitor Detector model with resolution: $\pm 0.1 \mu \mathrm{gm}^{-3}$ were used in this study (Fig. $2 \mathrm{~b}$ ). Studies have shown that mobile optical particle measurement method is a useful method for assessing spatial and temporal variability in the air pollutant concentrations (Tang and Wang 2006, 2007; Kaur et al. 2007; Weber and Litschke 2008; Weber 2009). In the present study, differences between spatial distribution of fine $\left(\mathrm{PM}_{1}\right)$ and coarse particle $\left(\mathrm{PM}_{\text {coarse }}\right)$ size fraction were examined while the spatial average of particle concentrations was calculated for coarse particle size fraction using methods as in Weber and Litschke (2008):

$$
P M_{\text {coarse }}=P M_{10}-P M_{1}
$$

where $P M_{10}$ and $P M_{1}$ represent the particulate material with aerodynamic diameters $\leq 10 \mu \mathrm{m}$ and $\leq 1 \mu \mathrm{m}$ respectively; while $P M_{\text {coarse }}$ is the differences between the particulate matters of aerodynamic diameter between 10 and $1 \mu \mathrm{m}$. Descriptive statistical techniques were used to find the average noise level and average particle concentrations for both weekdays and weekends. Correlation between particles concentration and noise were calculated to examine the spatiotemporal relationships between particles concentration, wind speed and noise levels. Correlation between particles concentration and 
noise were calculated in terms of Pearson's correlation coefficient " $r$ ", the magnitude of the correlation coefficients varies between \pm 1 . The spatial correlation between noise and particles, under conditions of turbulence mixing, was calculated for all measurement sites and their covariance was also assessed based on meteorological conditions and time of day when noise levels were measured.

\section{Result and discussion}

\section{Noise level at different sampling sites}

The noise level varied spatially and temporally over the periods of study, as detailed in Figs. 3, 4 and 5. These figures present variations in noise level, min, max and standard deviation for both WE and WE. Two major patterns are noticeable from these results: (1) the noise levels at different sample sites vary per time, much more during 12-2 p.m., with the standard deviation is greatest between 4 and 6 p.m.; and (2) the levels of noise were higher during the WD then WE periods. The highest level of noise was recorded during the afternoon between the hours of 12 noon and 2 p.m. with $\mathrm{L}_{\text {eq }}$ range of 98-120 dB(A) (Fig. 4). On the other hand, the least noise level was recorded during the evening; $L_{e q}$ range of 71-96 dB(A), within the hours of 4-6 p.m. in all measuring sites (Figs. 3, 4). The noise level during the early hours of the days between 7 and 9 a.m. with $L_{e q}$ range of 83-98 dB(A), were higher than that of evening periods in all study sites, but much more in measuring sites IV and VI (Figs. 3, 5). The reasons for these patterns of noise levels in the study area are obvious. During the early hour of the day, the majority

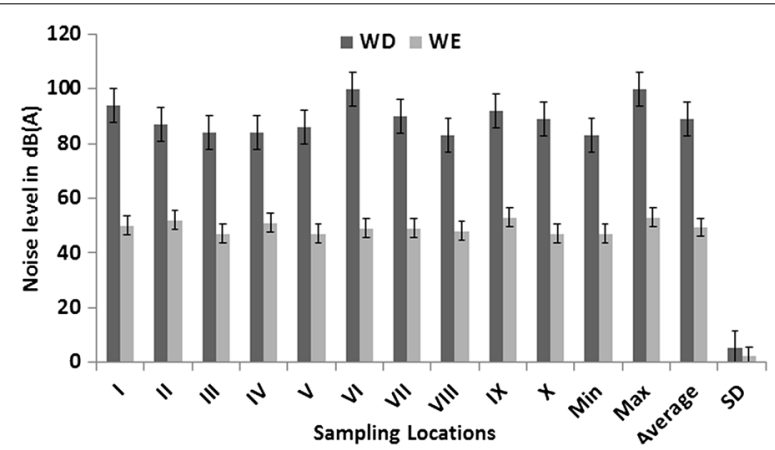

Fig. 3 Measurement of $L_{e q^{\prime}}$ at different sampling sites during 7-9 a.m. WE symbolizes weekend while WD symbolizes for the weekdays

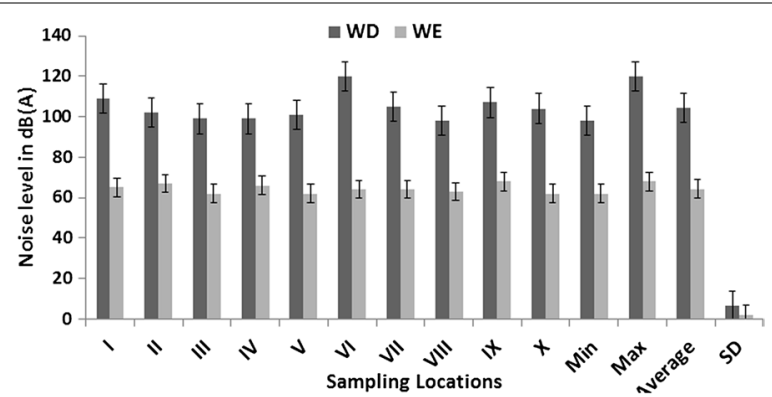

Fig. 4 Measurement of $L_{e q}$, at different sampling sites during 12-2 p.m. WE symbolizes weekend while WD symbolizes for weekdays 


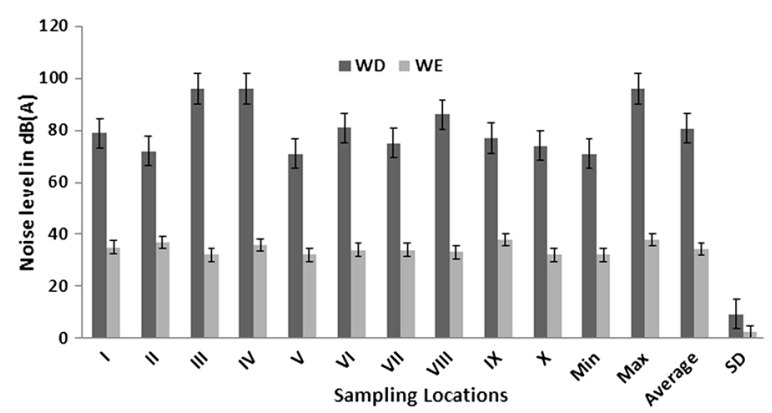

Fig. 5 Measurement of $L_{e q}$ at different sampling sites during 4-6 p.m. WE symbolizes weekend while WD symbolizes for weekdays

of sawmills industries are not usually functioning but most of the sawmill production are frequent during the afternoon periods. Observations during field work show that most of the sawmill machines were operational during the afternoon periods. The least noise level was recorded during the evening time (4-6 p.m.) because this period is the closing hours for many of sawmill industries, but much of the noise level recorded during this period were the effects of vehicles movements on nearby highway roads.

The results reveal not only daily variations in noise level but also variation between WD and WE. In general, a higher level of noise was observed during WD compared to WE (Figs. 3, 4, 5). In all study sites, the noise level $\mathrm{L}_{\mathrm{eq}}>50 \mathrm{~dB}(\mathrm{~A})$ was recorded during WD in all time episodes, especially at the measuring sites closer to sawmill engines (Fig. 6). Conversely, noise level during WE was slightly lower, with $\mathrm{L}_{\mathrm{eq}}$ range of 32-53 $\mathrm{dB}$ (A) (Fig. 6), but considerable small levels of noise were noted during the afternoon periods on some weekends with $\mathrm{L}_{\mathrm{eq}}$ range of $55-65 \mathrm{~dB}(\mathrm{~A})$. This is because some sawmill industries working during the afternoon in WE while the evening of WE is relatively the less noisy periods of time in the study area.

Besides, the noise level also varies spatially. The highest noise level was observed in the eastern part of the study area (Fig. 6). In this location, the noise level recorded in the majority of measuring sites were $\mathrm{L}_{\mathrm{eq}}>80 \mathrm{~dB}(\mathrm{~A})$, especially during WD. The reason for this might be because of the presence of several sawmills machines in the eastern part of the study area compared to other parts. Another reason for spatial variations in the noise level during the WD and afternoon periods is because different types of sawmill engines are being used around the study area (Fig. 7). The rate of noise pollution from these engines varies by their sizes, thus results in variation in spatial distribution of the noise, but much more in the eastern part of the study area. An unfortunate thing is the presence of some residential buildings in the eastern part of the study area. Though the present study does not investigate the societal and health implications of the high level of noise in this location, this will form part of the future study of this research. The general observation is that both weekdays and weekends noise levels exceed the noise limits standard by EPA for industrial noise levels. 


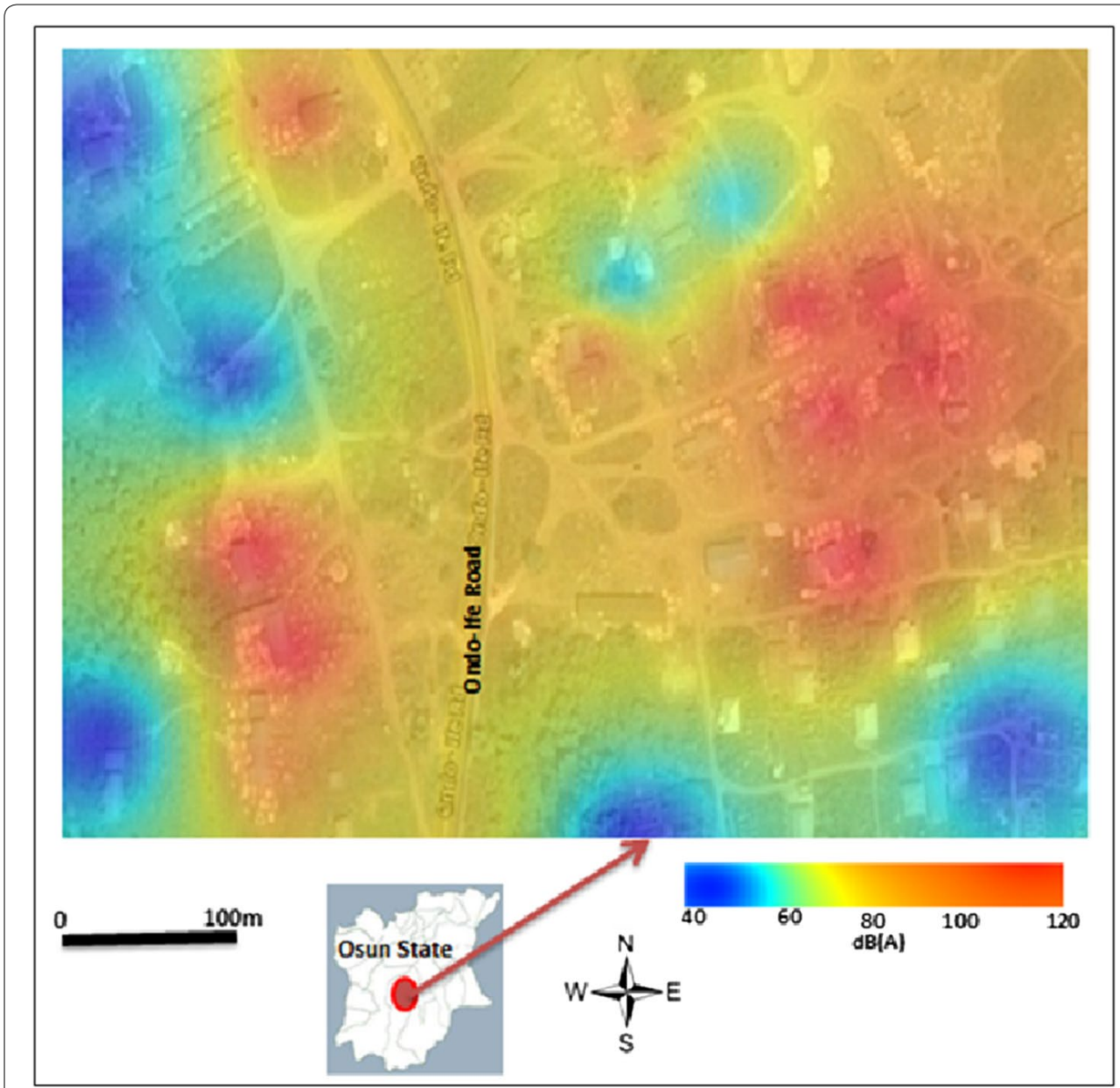

Fig. 6 Average spatial distribution of weekdays noise $L_{e q}$ over the period of two week's from 25th January to 9th of February 2015. Map of Osun state in green

What is obvious from this results is that the extreme average noise level of about $\mathrm{L}_{\text {eq }}$ 97-120 $\mathrm{dB}(\mathrm{A})$ are associated with the immediate neighbourhood of sawmill industrial areas during WD, while noise level of about $\mathrm{L}_{\text {eq }} 60-80 \mathrm{~dB}(\mathrm{~A})$ are recorded along streets and roadsides (Fig. 6). Contrary results were obtained during the WE, when the major source of noise was characterised by the roadsides (Fig. 8). These results imply that sawmill industries are the major sources of noise in the study area during the WD, but much of noise during the WE come from road traffics, especially along the highway of OndoIfe Rd (see Figs. 6, 8). Generally, noise levels were somewhat lower on the street compared to the highway during WE (Can et al. 2011).

\section{Meteorological and pollutant situation during the measurement periods}

Daily average temperature and wind speeds were characterised by distinct meteorological conditions. Figure 9 illustrates the time series of average daily temperature, wind speeds and direction over study periods when noise level and particle concentration measurements were taken. Table 1 presents daily averages of different meteorological quantities during week 1 and 2, with standard deviation (SD) and maximum (Max) values. Both weeks were characterized by different weed speeds condition. Largely, week 

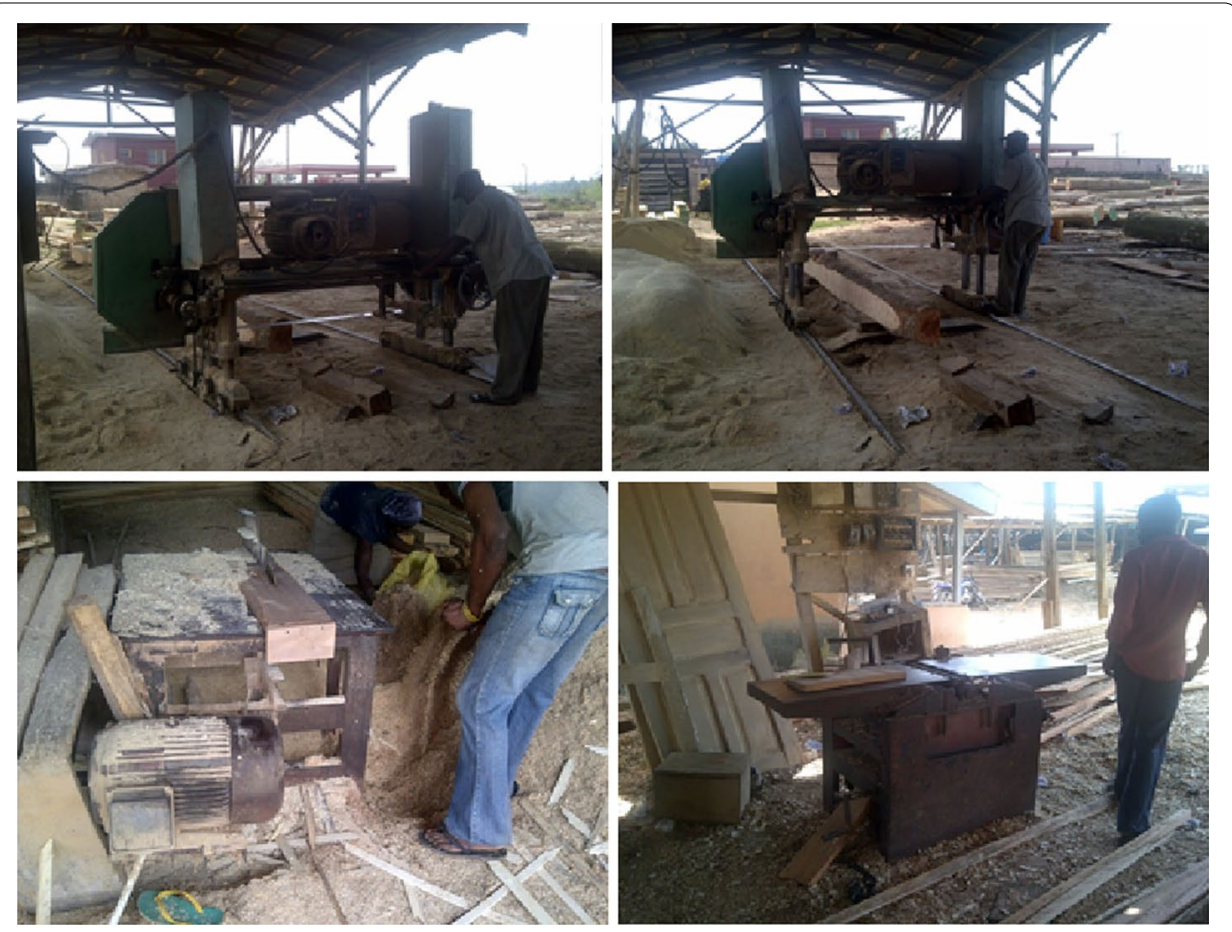

Fig. 7 Some sawmilling activities observed during the study. Source: photo taken during the field work

1 was characterized by weaker wind speeds, but higher average wind speeds, mainly from the Southwest direction, occurred during week 2 (Table 1; Fig. 9). The average wind direction was $302^{\circ}$ at $\pm 36.04 \mathrm{SD}$ and $256^{\circ}$ at $\pm 7.15 \mathrm{SD}$ for weeks 1 and 2 respectively. No precipitation occurred during the measuring periods throughout the weeks (Table 1). There appears to be relatively uniform average temperature for both weeks, but a distinct diurnal variation in temperature intensity was recorded. The midnight and early hours of the day were characterized by lower temperatures, ranging from 24 to $27^{\circ} \mathrm{C}$ while noon and afternoon periods were characterized by high temperature, ranging from 34 to $35^{\circ} \mathrm{C}$ (Fig. 9). During the measuring periods, the particle concentration varied temporally in all study sites with average larger for $\mathrm{PM}_{\text {coarse }}$ and smaller for $\mathrm{PM}_{1}$ (Table 1). The particle concentration patterns are influenced by meteorology conditions. Greater average particle concentrations occurred during week 1 compared to week 2 . This might be as a result of higher background aerosol from the sawmill industries and a higher percentage of relatively low wind speed which is more during measuring periods in week 1 compared to week 2 (Table 1 ).

\section{Correlation analysis of noise and meteorological situation during the measurement periods}

Finally, the relationship between noise levels and meteorology parameters were examined. The correlations results show a general weak relationship. The sound levels are weakly correlated to particle concentrations, perhaps because they have the common source-sawmill. For example, $\mathrm{PM}_{\text {coarse }}$ were weakly associated with noise levels in both week 1 and week 2 with correlation coefficients between $0.14<r>0.34$ (Table 2), and for 


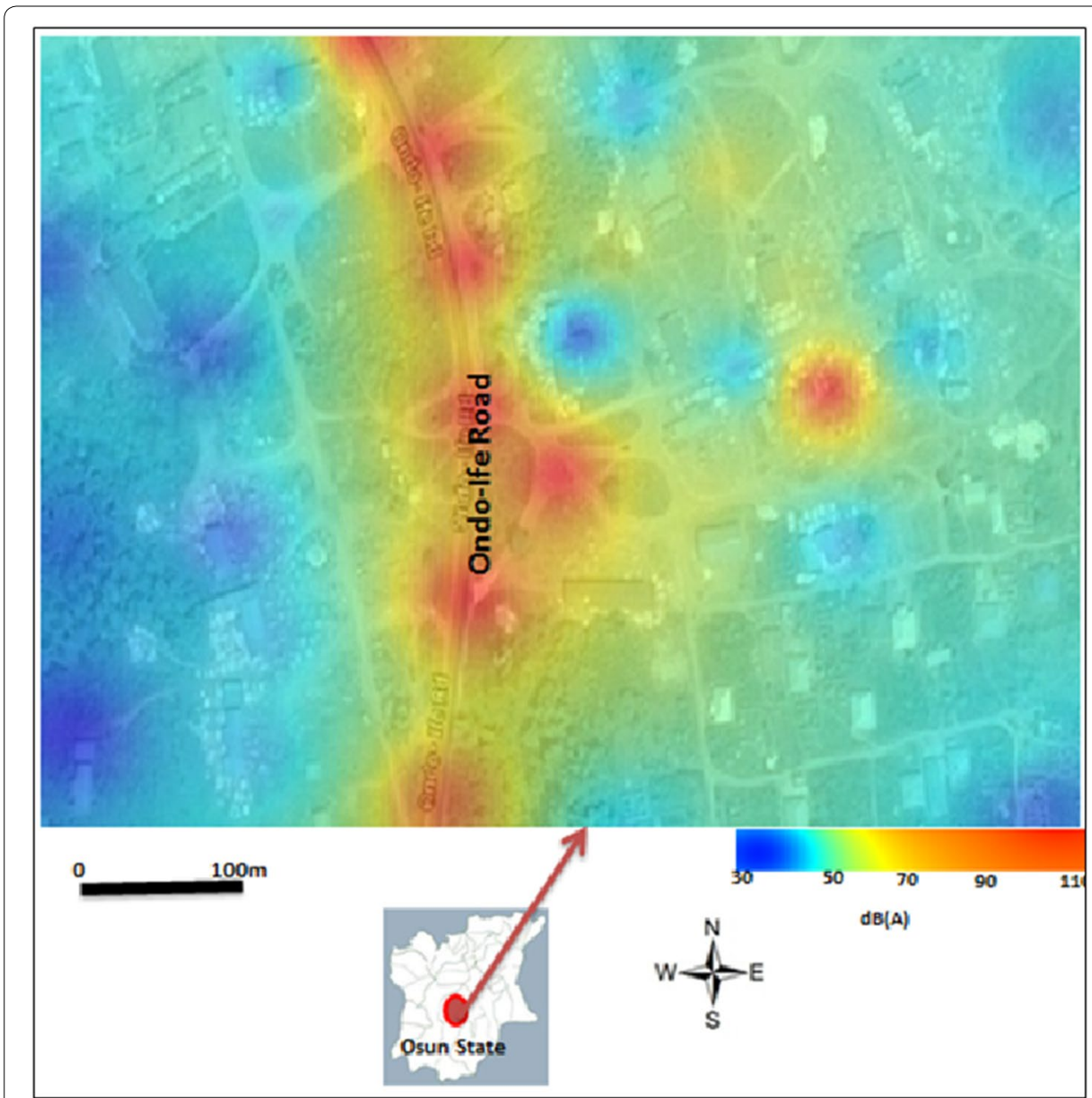

Fig. 8 Average spatial distribution of weekends noise $L_{e q}$ over the period of two week's from 25th January to 9th of February 2015. Map of Osun state in green

WD and WE, with correlation coefficients between $-0.16<\mathrm{r}>-0.14$ (Table 3). There are to be a slight relationship between noise level and $\mathrm{PM}_{1}$ during morning and afternoon periods of week 1 with $r=0.51$ and 0.58 respectively (Table 2). The slight correlation relationship between noise and $\mathrm{PM}_{1}$ during week 1 is thought to be as a result of weak in wind and change in wind direction (Table 1). Generally, noise levels demonstrate a very consistent spatial distribution along the vicinity of sawmill industries and this is independent of meteorology conditions, though, the change in wind direction and weak turbulent mixing, probably, resulted in the limited dispersion of particle during measurement in week 1 . This fact is evident when comparing the correlation relation between noise and meteorology conditions during the WD and WE as detailed in Table 3. There appear a very weak relationship between noise and particle concentrations for both WD and WE for $\mathrm{PM}_{1}\left(\mathrm{r}<0.35\right.$ for WD and $\mathrm{r}<0.25$ for WE) and $\mathrm{PM}_{\text {coarse }}(\mathrm{r}<0.20$ for WD and $r<0.14$ for WE). The relationship was negative between $L_{\text {eq }}$ and $\mathrm{PM}_{\text {coarse }}$ during the WE (Table 3), but moderate significant correlation relationship was obtained for $\mathrm{L}_{\mathrm{eq}}$ and the number of working sawmilling machines within each study site. The results show that the higher the number of sawmilling machines the more the noise especially during 

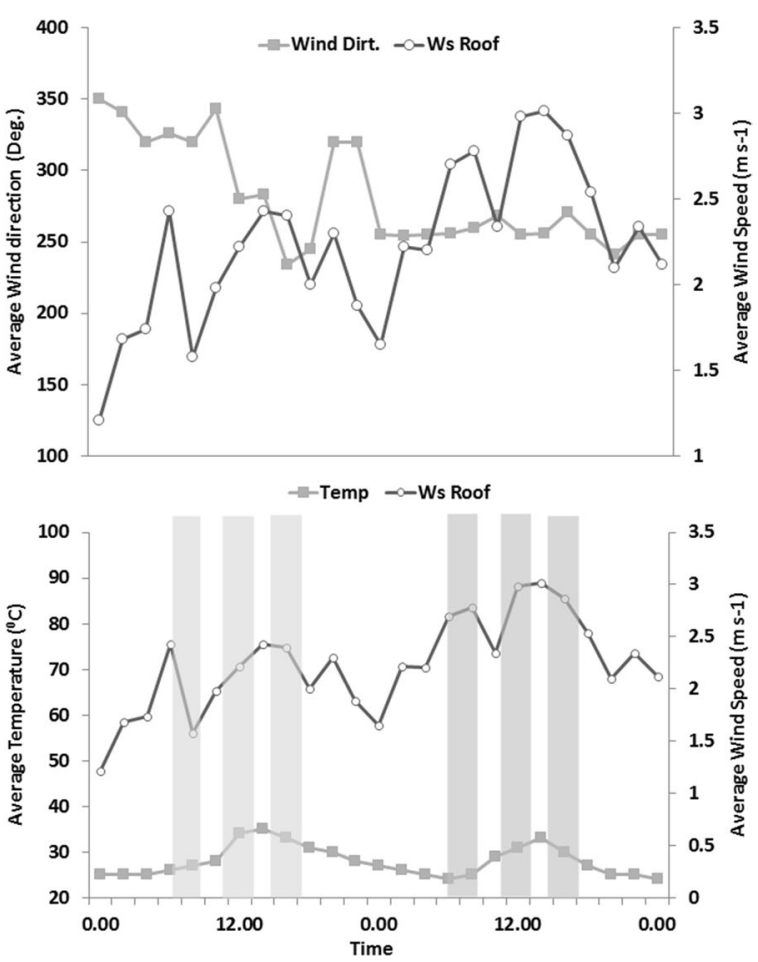

Fig. 9 Time series of different meteorological measurement over two week's from 25th January to 9th of February 2015. The grey shaded bars indicate time periods of noise and particle concentration measurements. Temp, Ws Roof and Wind Dirt stand for temperature wind speed and direction measurements, light gray indicate the week 1 while dark gray indicates the week 2

Table 1 Daily averages of different meteorological measures during both weeks

\begin{tabular}{lll}
\hline Measurement & Week 1 & Week 2 \\
\hline Noise level $\mathrm{L}_{\text {eq }}(\mathrm{dB}[\mathrm{A}])$ & $95.95 \pm 15.51(112)$ & $96.84 \pm 14.48(120)$ \\
$\mathrm{PM}_{1}\left(\mu \mathrm{g} \mathrm{m}^{-3}\right)$ & $32.21 \pm 12.82(53)$ & $28.18 \pm 9.73(45)$ \\
$\mathrm{PM}_{10}\left(\mathrm{\mu g} \mathrm{m}^{-3}\right)$ & $49.32 \pm 18.31(73)$ & $33.41 \pm 13.01(58)$ \\
$\mathrm{Ws}_{\left(\mathrm{m} \mathrm{s}^{-1}\right)}$ & $1.55 \pm 0.82(2.42)$ & $2.20 \pm 0.55(3.01)$ \\
Wind direction (deg.) & $302 \pm 36.04(350)$ & $256 \pm 7.15(268)$ \\
Rainfall $(\mathrm{mm})$ & 0.0 & 0.0 \\
Temperature $\left({ }^{\circ} \mathrm{C}\right)$ & $29.71 \pm 1.41(39)$ & $27.23 \pm 2.86(33)$
\end{tabular}

Standard deviation in italic values, maximum values in brackets Ws wind speed

Table 2 Correlations between noise level and particle concentrations during the two weeks of measurement

\begin{tabular}{lccc}
\hline Time & Ws vs $\mathbf{P M}_{\mathbf{1}}$ & $\mathbf{L}_{\mathbf{e q}}$ vs $\mathbf{P M}_{\mathbf{1}}$ & $\mathbf{L}_{\mathbf{e q}} \mathbf{v s}_{\mathbf{~}} \mathbf{P M}_{\text {coarse }}$ \\
\hline W1 & & & $0.20^{*}$ \\
Morning & 0.48 & 0.51 & 0.34 \\
Afternoon & 0.49 & 0.58 & $-0.12^{*}$ \\
Evening & $-0.19^{*}$ & $0.21^{*}$ & $0.19^{*}$ \\
W2 & & & 0.34 \\
Morning & 0.22 & 0.28 & $0.14^{*}$ \\
Afternoon & 0.21 & 0.39 & 0.22 \\
Evening & -0.14 & & \\
\hline
\end{tabular}

* Not significant at $\mathrm{p}<0.05$. W1 and W2 stand for week 1 and 2 respectively. Ws represents wind speed 
Table 3 Correlations between noise level, number of working sawmilling machines and particle concentrations during measurement (comparing WD and WE)

\begin{tabular}{|c|c|c|c|}
\hline Measurment & Time & WD & WE \\
\hline \multirow[t]{3}{*}{$L_{\text {eq }}$ vs no of working sawmilling machines } & Morning & 0.24 & 0.21 \\
\hline & Afternoon & $0.62^{*}$ & 0.29 \\
\hline & Evening & 0.19 & 0.03 \\
\hline \multirow[t]{3}{*}{$\mathrm{L}_{\mathrm{eq}} \mathrm{Vs}^{\mathrm{PM}} \mathrm{M}_{1}$} & Morning & 0.31 & 0.20 \\
\hline & Afternoon & 0.32 & 0.24 \\
\hline & Evening & 0.34 & 0.14 \\
\hline \multirow[t]{3}{*}{$\mathrm{L}_{\text {eq }}$ vs $P M_{\text {coarse }}$} & Morning & -0.17 & -0.14 \\
\hline & Afternoon & 0.20 & -0.18 \\
\hline & Evening & -0.18 & -0.16 \\
\hline
\end{tabular}

* Significant at $p<0.05$. WD and WE represent weekdays and weekends respectively

the WD with $r=0.62$ (Table 3), though change in wind direction and turbulent mixing affects both the noise level and particle concentrations.

\section{Conclusion}

This study draws upon two set of data; noise measurement and meteorological data to examine spatial and temporal variation in wind and it influences on the noise level. The samples measurements were conducted during the period from 26 January through 9 February 2015 in sawmill industrial area in Ile-Ife. Using mobile measurements, the study aims at assessing effects of wind speed/direction on industrial-induced noise. The results from this study revealed that: (1) noise levels in the study area are by far exceeding the EPA noise standard for industrial area; (2) noise level demonstrate a very consistent spatial distribution, higher along the vicinity of sawmill industries and this is independent of meteorology conditions; (3) there are slight correlation relationship between noise and $\mathrm{PM}_{1}$ due to weak turbulent mixing, during week 1 , resulted from limited dispersion of particle during measurement; (4) extreme average noise levels are associated with the immediate neighbourhood of sawmill industrial areas during WD compared to streets and road annexes of the study area. However, noise levels were more along the highway roadside during WE when the majority of the sawmill industries were not in operation.

The results from this study revealed that, in many cases, particle sizes do not have a similar response to meteorological conditions and that wind speeds and directions have significantly influence on both noise level and particle concentration (Jamriska and Morawska 2008; Nicolas et al. 2009; Can et al. 2011). These results imply that particle concentrations and distributions are strongly varied with wind speed and direction as they move away from the major source (Zhang et al. 2004; Muzet 2007; Owoade et al. 2013). The influences of meteorological conditions on noise levels appears much more complex. The results show that the correlation between noise level and PM1 appears relatively moderate during weak turbulent metrological conditions. Previous studies have earlier reported a moderate correlation between noise level and atmospheric particles. The foremost studies include Weber and Litschke (2008) and Davies et al. (2009) which established a slight relationship between some particle concentrations and noise levels. The major finding of the present study is that noise levels and atmospheric particles sensitive to wind speeds and directions as they cover distances from the sources. 
It is also obvious from this study that sawmill mechanical noise is the major sources of the noise in the study area, noise that results from all kinds of sawmill operation and power capacity engines. Generally, noise levels demonstrate very consistent spatial distributions along locality of sawmill industries and this is independent of meteorology conditions. But, weak turbulent mixing results to moderate association between noise level and some particle concentrations. The spatial correlation between particle concentrations and the noise level was largely weak as a result of higher turbulent mixing and some changes in the direction of the ambient wind during measurement periods.

\section{Authors' contributions}

AA played the leading role in the conception and every aspect of this study. EFO contributed in data collection, data analysis, and other various levels of expertise. Both authors read and approved the final manuscript.

\section{Competing interests}

The authors declare that they have no competing interests.

Received: 13 May 2016 Accepted: 13 October 2016

Published online: 28 October 2016

\section{References}

Adejuwon JO, Jeje LK (1975) Land element of the environmental system of ife area. In: Ojo A (ed) Environment resource base project, no 2. Department of Geography, University of Ife, Ife

Ayanlade A (2009) Seasonal rainfall variability in Guinea Savanna part of Nigeria: a GIS approach. Int J Clim Change Strateg Manag 1(3):282-296

Ballesteros MJ, Fernandez MD, Quintana S, Ballesteros JA, Gonzalez I (2010) Noise emission evolution on construction sites. Measurement for controlling and assessing its impact on the people and on the environment. Build Environ 45(3):711-717

Burrough PA, Rachael AM (1998) Principal of geographical information systems. Oxford University Press, Oxford

Can A, Rademaker M, Van Renterghem T, Mishra V, Van Poppel M, Touhafi A, De Baets B, Botteldooren D, Theunis J (2011) Correlation analysis of noise and ultrafine particle counts in a street canyon. Sci Total Environ 409(2011):564-572

Chung JH, Des Roches CM, Meunier J et al (2005) Evaluation of noise-induced hearing loss in young people using a webbased survey technique. Pediatrics 115:861-867

Davies HW, Vlaanderen JJ, Henderson SB, Brauer M (2009) Correlation between coexposures to noise and air pollution from traffic sources. Occup Environ Med 66:347-350

De Vos P, Van Beek A (2011) Environmental noise. Encycl Environ Health 1:476-488

Den Boer LC, Schroten A (2007) Traffic noise reduction in Europe. Health effects, social costs and technical and policy options to reduce road and rail traffic noise. Report, CE Delft. http://www.ce.nl. Accessed 15 Mar 2014

EEA (2014) Noise in Europe 2014. Publications Office of the Europea Union, Luxembourg

FEPA (1991) National interim guidelines and standards for industrial effluent, gaseous emissions and hazardous waste in Nigeria. Federal Environmental Protection Agency Decree. http://www.placng.org/new/laws/F10.pdf. Accessed 15 Mar 2014

Foraster M (2013) Is it traffic-related air pollution or road traffic noise, or both? Key questions not yet settled! Int J Public Health 58(5):647-648

Jamriska M, Morawska LK (2008) The effect of temperature and humidity on size segregated traffic exhaust particle emissions. Atmos Environ 42:2369-2382

Kaur S, Nieuwenhuijsen MJ, Colvile RN (2007) Fine particulate matter and carbon monoxide exposure concentrations in urban street transport microenvironments. Atmos Environ 41:4781-4810

Lee HY (2014) Long-term evolution of campus noise emissions: a case of new university development. J Environ Plan Manag 57(8):1169-1182

Muzet A (2007) Environmental noise, sleep and health. Sleep Med Rev 11:135-142

Nicolas JF, Yubero E, Pastor C, Crespo J, Carratalá A (2009) Influence of meteorological variability upon aerosol mass size distribution. Atmos Res 94:330-337

Ojo O (1977) The climates of West Africa. Heinemann Educational Books Ltd, Oxford

Owoade OK, Jegede OO, Ayoola MA, Fawole OG, Bashiru MI, Olise FS, Ogundele LT (2013) Concentrations of particulate matter from an iron and steel smelting plant located along a busy high way in southwestern Nigeria. Ife J Sci 15(1):31-39

Oyedepo SO (2012) Noise pollution in urban areas: the neglected dimension. Environ Res J 6(4):259-271

Oyedepo OS, Saadu AA (2009) A Comparative study of noise pollution levels in some selected areas in Ilorin metropolis, Nigeria. Environ Monit Assess 158:155-167

Pathak V, Tripathi BD, Mishra VK (2008) Evaluation of traffic noise pollution and attitudes of exposed individuals in working place. Atmos Environ 42:3892-3898

Pokhrel RM, Jiro K, Shinya T (2013) A kriging method of interpolation used to map liquefaction potential over alluvial ground. Eng Geol 152(1):26-37 
Samanta DK, Pal D, Lohar B (2012) Interpolation of climate variables and temperature modelling. Theor Appl Climatol 107:35-45

Sonibare JA, Akeredolu FA, Latinwo I, Solomon BO (2004) Impact of tanneries on ambient noise levels in Kano, Nigeria. Afr J Environ Assess Manag 8:1-18

Sørensen M, Hvidberg M, Andersen ZJ, Nordsborg RB, Lillelund KG, Jakobsen J, Tjønneland A, Overvad K, RaaschouNielsen O (2011) Road traffic noise and stroke: a prospective cohort study. Eur Heart J 32(6):737-744

Tang UW, Wang ZS (2006) Determining gaseous emission factors and drivers's particle exposures during traffic congestion by vehicle following measurement techniques. J Air Waste Manag Assoc 56:1532-1539

Tang UW, Wang ZS (2007) Influences of urban forms on traffic-induced noise and air pollution: results from a modelling system. Environ Model Softw 22:1750-1764

Tetreault LF, Perron S, Smargiassi A (2013) Cardiovascular health, traffic-related air pollution and noise: are associations mutually confounded? A systematic review. Int J Public Health 58(5):649-666

Ugwuanyi J, Ahemen UI, Agbendeh AA (2005) Assessment of environmental noise pollution in Makurdi metropolis, Nigeria. Zuma J Rure Appl Sci 6:134-138

Weber S (2009) Spatio-temporal covariation of urban particle number concentration and ambient noise. Atmos Environ 43:5518-5525

Weber S, Litschke T (2008) Variation of particle concentrations and environmental noise on the urban neighbourhood scale. Atmos Environ 42:7179-7183

WHO (2005) United Nations road safety collaborations. A handbook of partner profiles. World Health Organisation, Geneva

WHO (2011) Burden of disease from environmental noise—quantification of healthy life years lost in Europe. WHO Regional Office for Europe, Bonn

WHO (2013) Review of evidence on health aspects of air pollution—REVIHAAP project. Technical report. http://www. euro.who.int/_data/assets/pdf_file/0004/193108/REVIHAAPFinal-technical-report-final-version.pdf. Accessed 19 Mar 2014

Zhang KM, Wexler AS, Zhud YF, Hinds WC, Sioutas C (2004) Evolution of particle number distribution near roadways. Part II: the'road-to-ambient' process. Atmos Environ 38:6655-6665

\section{Submit your manuscript to a SpringerOpen ${ }^{\circ}$ journal and benefit from:}

- Convenient online submission

\section{- Rigorous peer review}

- Immediate publication on acceptance

Open access: articles freely available online

- High visibility within the field

- Retaining the copyright to your article

Submit your next manuscript at $\boldsymbol{\nabla}$ springeropen.com 